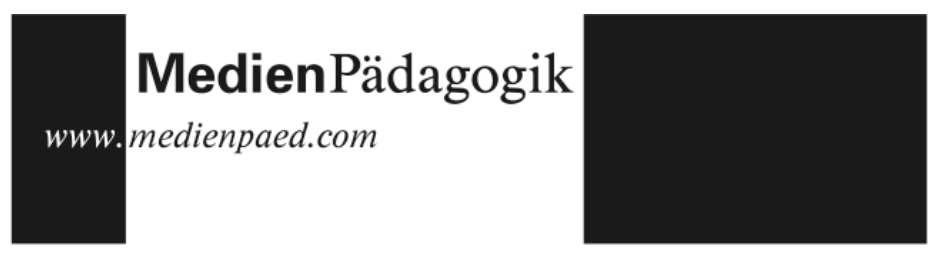

Rezensionen

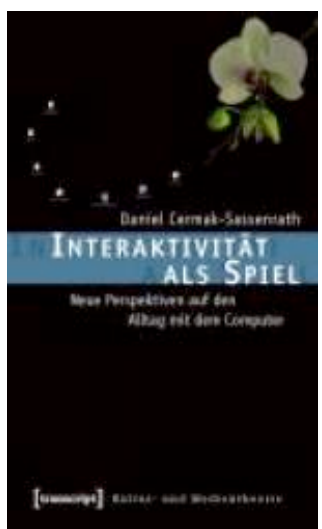

Daniel Cermak-Sassenrath

Interaktivität als Spiel

Neue Perspektiven auf den Alltag mit dem Computer

Bielefeld: transcript, 2010. 382 Seiten

ISBN: 978-3-8376-1303-2

$€ 29.80 ;$ CHF 33.60

\title{
Vom spielerischen Charakter des interaktiven Umgangs mit dem Computer
}

Im Jahr 2000 stellte Claus Pias im Rahmen seiner Dissertation die bis dato umfangreichste phänemenologische Analyse des Computerspiels in

Deutschland vor. Zehn Jahre später folgt Daniel Cermak-Sassenraht diesen Ausführungen und erweitert sie um eine neue Perspektive: auch die alltägliche Computernutzung nimmt immer mehr Elemente aus dem Computerspiel auf. Cermak-Sassenraths Monographie - Grundlage bildet seine von Frieder Nake und Claus Pias betreute Doktorarbeit - folgt dabei einer interdisziplinären Perspektive, die sowohl in der geisteswissenschaftlichen Medienwissenschaft, als auch in den ingenieurswissenschaftlichen Human Computer Interaktion $(\mathrm{HCl})$ Studien beheimatet ist. In - exklusive Vorwort - sieben Kapiteln widmet sich Cermak-Sassenrath sowohl dem Umgang mit Medien, dem Wesen des Spiels, der Bedeutung von Erzählungen als Narrative (darunter auch dem interactive storytelling), als auch neueren Konzepten der $\mathrm{HCl}$ wie dem calm computing oder dem ubiquitous computing. Durch die Verbindung dieser unterschiedlichen Theorien, Ansätze und vor allem Perspektiven erhält die Arbeit den Charakter einer post-modernen Bricolage. Hier stehen Ansätze der Kommunikationswissenschaft, neben hermeneutischen Analysen der Medienwissenschaft, anthropologischen Analysen des Spiels und Konzepten aus der Informatik. Dies ist Stärke und Schwäche der Arbeit zugleich. Eine Stärke wird es durch die große Breite der Informationen, mit denen Leser/innen vertraut werden. So findet sich kaum ein Bereich der Computerspielforschung der nicht angesprochen wird. Zur Schwäche wird dieses Vorgehen dadurch, dass sich auf den 375 Seiten der Monographie durchaus Redundanzen finden - Konzepte wie die Bedeutung des 


\section{Rezensionen}

Spiels werden wiederholt und (leider) durchaus repetitiv aufgegriffen. Notwendigerweise wird es somit auch zum Problem, dass der Autor nicht in jedem Bereich der Forschung gleich bewandert ist bzw. sein kann. Gerade die Exkurse zur Wirkung von Computerspielen und deren ökonomische Bedeutung sind für Kommunikationswissenschaftler/innen ein wenig befremdlich.

Gelegentlich erscheint Cermak-Sassenraths Arbeit wie ein Rückgriff auf die vor allem Anfang der 2000er Jahre geführte Debatte zwischen Ludologen und Narratologen, wobei Cermak-Sassenrath sich eindeutig auf die Seite der Ludologen schlägt - spricht seine zentrale These ja von der verspielten Nutzung von Computertechnologie im Allgemeinen. Die aufgezeigten Belege und Beispiele hierfür erscheinen vor dem Hintergrund einer spätestens seit der Auseinandersetzung von Jeesper Juul (Ludologe) und Henry Jenkins (Narratologe) als gelöst erscheinende Debatte zwischen beiden Positionen ein wenig anachronistisch. Aussagen wie «Kauft jemand ein Computerspiel, ist er offenbar nicht auf der Suche nach einer story» (S. 268) oder «Die Geschichten die in Computerspiele vorkommen scheinen nur shallow catalogues of popular culturet, zu sein» (S. 258), belegt mit Aussagen von Jesper Jull und Janet Murray aus den späten 1990er Jahren entsprechen nicht mehr dem Stand der Forschung bzw. der Entwicklung der Spieleindustrie.

Zusammenfassend bleibt dies eine Arbeit, die vor allem für Forscher/innen aus dem Bereich der Informatik oder Human Computer Interaction Studien von Interesse sein dürfte, da sie die Verbindungen dieser Disziplinen mit geistes- und sozialwissenschaftlichen Ansätzen herstellt. Als rein sozialbzw. geisteswissenschaftliche Arbeit scheitert Cermak-Sassenrath jedoch daran, die rasante Entwicklung sowohl im Bereich der Computerspielentwicklung als auch in der Forschung dazu aufzuzeigen.

Sven Jöckel 